Femando Urrea Giraldo Universidad del Valle, Cali
Wald or Botero Arias

Universidad del Valle, Cali
Hemán Dańo Herrera Arce

Universidad del Valle, Cali

José Ignacio Reyes Sema

Universidad del Valle, Cali

\title{
Afecto y elección de pareja en jóvenes de sectores populares de Cali ${ }^{1}$
}

\begin{abstract}
Resumen: Este artículo explora las lógicas de producción de afectos y elección de pareja en los jóvenes de sectores popula res heterogéneos de la ciudad de Cali (Colombia), según factores de clase, género y raza. Sin pretender entrar directamente en la conyugalidad, de todos modos el texto sí incursiona en el asunto de la elección de pareja, bajo las restric ciones del ciclo de vida adolesc ente y postadolescente de nuestro programa de investigación a tra vés del noviazgo, eventualmente con la opción de cohabitar y tener una prole; de acuerdo con la información recogida a nivel de las entrevistas y los grupos focales. En segundo lugar, al tener la disposic ión de una información estadístic a a través de una serie de encuestas de hogares entre 1998 y el 2003 para Cali y la región urbana del Valle del Cauca, en donde se encuentra Cali, sobre población afrocolombiana y no afrocolombiana, hemos podido intentar una primera aproximación al fenómeno de la homogamia racial de los hogares completos (con presencia de cónyuge), estableciendo los nexos necesarios con los datos cualitativos para mirar desde una perspectiva macro social el comportamiento de esas lógicas en los grupos jóvenes. Por ello, los factores de clase, género y raza son vistos a través de la categoría de homogamia racial, en el sentido de acercarse a los constreñimientos sociales del ejerc ic io de la sexualidad, el afecto y el intento de conformación de uniones en la sociedad caleña.
\end{abstract}

Palabras claves: afecto, amor romántico, elección de pareja, género, cla se social y homogamia racial.

Copyright (c) 2006 by Revista Estudos Feministas

${ }^{1}$ Artículo con base en la ponencia presentada en el "Seminário Raça, Sexualidade e Saúde: Perspectivas Regionais". Mesa 2 "Raça, Afeto e Conjugalidade". Centro Latino-Americano em Sexualidade e Direitos Humanos/ IMS/UERJ ; Instituto Oswaldo Cruzl FIOCRUZ; Centro de Estudos AfroBrasileiros/UCAM; 3, 4 y 5 de novembro de 2004. Rio de J a neiro. Esta versión publicada ha tenido algunas modificaciones sugeridas por el comité de pares
Para papá de mis hijos quiero un hombre amoroso, especial, tierno, detallista, es un hombre $10 \ldots$ Los hombres aquí del barrio son posesivos, es muy común que los hombres le peguen a las mujeres. Son patanes, mal hombres, machistas e infieles... La vida en Charco Azul² es más fuerte para una mujer que para un hombre, porque no es fácil conseguir un hombre bueno... Yo deseo conseguir un hombre de afuera (del barrio), ellos son mejores. Pilar, mujer negra de 27 años, soltera con un hijo de 5 años, 9o grado de estudios, desempleada

\section{Introducción}

Esta ponencia se inscribe en un programa de investigación sobre adolescentes y postadolescentes, 
de la Revista Estudos Feministas, a quienes se les agradece sus comentarios; si bien la responsabilidad del contenido es a sumida por sus autores.

${ }^{2}$ Bario de clases populares bajas del oriente de la ciudad, con alta concentración de población negra.

${ }^{3}$ Proyecto Cidse-Ird-Colciencias, "Movilidad, urbanización e identidades de las poblaciones afrocolombianas en la región Pa cífic a", 1996-2000.

${ }^{4}$ En la representación del mundo andino en América Latina, en términos émicos la categoría mestizo hace referencia a la mezcla interracial del español y el indígena, con todas las posibles variaciones fenotípicas de dicha mezcla. Igualmente, la expresión mula to hace referencia a la mezcla racial blanco/negro en todas sus modalidades. Sin embargo, también es frecuente la mezcla indígena/negro (término zambo), pero para efectos de la connota ción émica puede caer como negro o mulato, dependiendo de la mayoro menoroscuridad de piel. ${ }^{5}$ Alrededor de 30 entrevistas a jóvenes, mujeres y hombres, a dolesc entes, esc ola riza dosy no escola riza dos; 25 estudia ntes universitarios; 4 grupos focales con adolescentes.

6 Véanse Pedro QUINTíN, Hector Fá b io RAMÍREZy Femand o URREA, 2000; URREA y QUNTÍN, 2000; URREA, 2002; URREA, Mary Lily CONGOLINO y Hernán Da río HERRERA, 2003; Olivier BARBARY y URREA, 2004; Ma ra VIVEROS y Franklin Gil HERNÁNDEZ, 2006; y URREA, CONGOUNO, HERRERA, José Ig nacio REYES e Waldor BOTERO, 2006.

7 Asumimos como población adolescente el grupo poblacional de mujeres y hombres que fluctúa arbitrariamente entre 10 12 y 18-20 años, y que en las diferentes sociedades occidenta les desde mediados del siglo XX se le ha asignado socialmente una etapa de moratoria, a través del sistema escolar, antes de vincularse a las actividades mujeres y hombres en su mayor parte gente negra pero también mestiza, de sectores populares y clases medias bajas en la ciudad de Cali, en el cual se han venido estudiando diferentes dimensiones sobre la construcción de las masculinidades y feminidades, las prácticas de sexualidad y su interacción con los programas de Salud Sexual y Reproductiva (SSR). A su vez, este programa ha estado relacionado con otro más amplio sobre una caracterización sociodemográfica y socioeconómica de la población negra/mulata en el contexto de una ciudad mestiza y sus dinámicas sociopolític as. ${ }^{3}$ En cambio, una temática más específica como la elección de pareja entonces ha sido apenas un subproducto, sin que haya formado parte de un componente especial, además restringido a los grupos etáreos jóvenes y ciclo de vida adolescente y postadolescente, lo cual señala ya las limita ciones para entrar a un a nálisis de la conyugalidad.

Los jóvenes negros y mestizos, ${ }^{4}$ hombres y mujeres, que formaron parte del estudio cualitativo, en su conjunto proceden de sectores populares del oriente de Cali y algunos de clases medias bajas. Hay jóvenes desertores escolares, otros-as escolarizados de barrios populares diversos, al igual que estudiantes universitarios negros y mestizos de la Universidad del Valle de varios planes de estudio. ${ }^{5}$

Pero al lado del estudio cualitativo se cuenta con una información estadística demográfica sobre la población afrocolombiana para la ciudad de Cali y la región urbana del Valle del Cauca, comparada con el conjunto de la población mestiza y blanca, recogida durante el programa de investigaciones Cidse-Ird llevado a cabo hasta la actualidad. Igualmente, para el estudio sobre los programas de SSR entre los jóvenes negros se ha contado con dos encuestas sobre práctic as de sexualidad aplicadas a usuarios de estos programas en dos tipos de poblaciones: estudiantes de secundaria de colegios populares del oriente de la ciudad y estudiantes de la Universidad del Valle.

A partir de esta clase de información y de una reflexión teórica sobre los ejes temáticos antes mencionados, que han dado por resultado varias public a ciones, ${ }^{6}$ se ha trabajado esta ponencia. Su objetivo consiste en explorar las lógicas de producción de afectos y elección de pareja en los jóvenes de sectores popula res heterogéneos, según factores de clase, género y raza. Sin pretenderentrardirectamente en la conyugalidad, de todos modos el texto sí incursiona en el a sunto de la elección de pareja, bajo las restric ciones del cic lo de vida a dolescente y postadolescente ${ }^{7}$ de nuestro programa de investigación 
"adultas". La llamada adolescencia es una construcción histórica de Occidente, al igual que la infancia, y que en cierto modo constituye una extensión de esta última. La postadolescencia corresponde a una prolongación de la moratoria social a medida que se expande en el período de vida la educación postsecundaria, que para efectos del estudio empínco corresponde al grupo etáreo arbitrario entre 1820 años y 24-26 años. Por supuesto, la mora toria social varía considerablemente de una clase social a otra, además de que se presentan importantes diferencias porgénero en la vivencia de esa moratoria. Asumimos provisionalmente y en forma descriptiva este concepto de moratoria apoyándonos en Mario MARGULLIS y Marc elo URRESTI, 1998.

${ }^{8}$ Encuestas llevadas a cabo por el proyecto Cidse-Ird o el Dane (Departamento Nacional de Esta dística de Colombia).

${ }^{9}$ La práctica recurente a establecer una relación de pareja (matrimonial o de noviazgo estable) entre dos personas con características raciales similares. Lo contrario, la heterogamia racial se refiere a favorecerlasmezc lasracialesen las parejas. Para diversos autores la homogamia racial no está separada de una homogamia socioeconómica (mayorfrecuencia de conformación de parejas entre personas que tienen condiciones socialesparecidas). Veral respecto, Clara ARAÚJ O y Celi SCALON, 2005, en lo que respecta a la sociedad brasileña.

10 Hogares que cuentan con cónyuge presente. Pueden ser nucleares, extensoso compuestos.

11 BARBARY y URREA, 2004.

12 Informe Cidse ECV 2003 (DANE, 2004).

13 URREA y QUINTÍN, 2000.

14 URREA y QUINTÍN, 2000.

15 URREA, CONG OLNO y HERRERA, 2003. a través del noviazgo, eventualmente con la opción de cohabitary tener una prole; de acuerdo con la información recogida a nivel de las entrevistas y los grupos focales. En segundo lugar, al tener a disposición una información estadística a través de una serie de encuestas de hogares entre 1998 y el 2003 para Cali y la región urbana del Valle del Cauca, ${ }^{8}$ en donde se encuentra Cali, sobre población afrocolombiana y no afrocolombiana, hemos podido intentar una primera aproximación al fenómeno de la homogamia racial ${ }^{9}$ de los hogares completos, ${ }^{10}$ estableciendo los nexos necesarios con los datos cualitativos para mirardesde una perspectiva macro social el comportamiento de esas lógicas en los grupos jóvenes. Por ello, los factores de clase, género y raza son vistos a través de la categoría de homogamia racial, en el sentido de acercarse a los constreñimientos sociales del ejercic io de la sexualidad, el afecto y el intento de conformación de uniones en la sociedad caleña.

La población afrocolombiana o negra/mulata corresponde aproximadamente entre el 20 y el $22 \%$ de la población total del país, de 8,6 a 9,5 millonesde personas, ${ }^{11}$ configura ndo la "minoría étnico-racial" más importante en términos demográficos de la sociedad colombiana. En la ciudad de Cali, aproximadamente un $32 \%$ de la población total es negra/mulata y para la región urbana del Departamento del Valle del Cauca, del cual Cali es la capital, un poco más de la cuarta parte de la población, 1,1 millones de personas. ${ }^{12}$ Alrededor del $72 \%$ de los hogares a frocolombianos de Cali residen en barrios popula res y de clases medias bajas del oriente y centro-oriente de la ciudad. ${ }^{13}$ A su vez, en estos espacios hay una amplia extensión de barrios en peores condiciones de urbanización, denominados "invasiones". Allí la concentración de gente negra pasa del $60 \% .{ }^{14}$

Como se indicaba en un trabajo previo, ${ }^{15}$ en el caso de Cali se da un significativo desbalance demográfico hombres/mujeres juvenil entre los más pobres según condición racial: la rela ción porcentual entre los dos sexos en los hogares afrocolombianos para los menores de 20 años es mucho más masculina. Un poco más del $60 \%$ de la población masculina en los hogares a frocolombianos del primer quintil que viven en el oriente de la ciudad es menor de 20 años, mientras las mujeres alcanzan un poco menos del $50 \%$. Se tra ta así, sobre to do para el primerquintil de ingresos de una población muy joven asociada a condiciones de extrema pobreza, más acentuada en los hogares a frocolombia nos.

El a nterior contexto sociodemográ fic o urbano, en el cual residen la totalidad de los entrevistados de nuestro 
${ }^{16}$ Pierre BOURDIEU, 1979.

17 "Es el instrumento de ruptura entre un punto de vista objetivista y la acción sin agente que supone el estructuralismo (al recumir, por ejemplo, a la noción de inconsciente). La estrategia es el producto del sentido práctico como sentido del juego, de un juego social particular, históricamente definido, adquirido desde la infancia a través de la participación en actividades sociales" (BOURDIEU, 1987).

18 Ver Edward SHORTER, 1977; Eliza beth BADINTER, 1980 y 1986; Anthony GIDDENS, 1992; Martine SEGALEN, 1993; Gilles LPOVEISKY, 1997; Serge CHAUMIER, 2001; y François de SINGLY, 2001.

${ }^{19}$ C HAUMIER, 2001. programa de investigación sobre sexualidad y raza de jóvenes adolescentes y postadolescentes, es importante tenerlo presente para entender los espacios de vida o de producción de habitus en el sentido de Bourdieu, ${ }^{16}$ los cuales van a impregnartodas las dimensiones de la vida subjetiva de laspersonas que allí viven, entre ella sel campo erótic o afectivo y de elección de pareja. Por otro lado, el concepto de estrategias en Bourdieu ${ }^{17}$ esfundamental para contextualizar la elección de pareja, en cuanto esta categoría hace referencia a un tipo de acción en la trayectoria individual de selec ción de pa reja sexual/a fec tiva en la dirección de noviazgo o de una eventual cohabitación y conformación de prole, en relación con un conjunto de capitales disponibles (escolar, cultural, social, económico, simbólico, social, corporal) que son puestos en juego en un mercado erótico-afectivo.

\section{Afecto y amor romántico en jóvenes de clases populares}

Por afecto en esta ponencia consideramos el sentimiento amoroso que establece un lazo de mutua interdependencia emocional entre dos o más individuos, casi siempre con expresiones visibles que refuerzan el ego de los individuos en juego. Históric amente su desa rrollo ha estado atado a la ideología del amor romántico, con ma yores manifesta ciones desde el siglo XIX y a lo largo del sig lo XX, partic ula rmente en el campo erótic 0 , con un peso creciente en la elección de pareja y en las relaciones interpersonales no necesariamente conyugales hacia las últimas cuatro décadas. Se trata entonces de una forma histórica del sentimiento en las relaciones interpersonales producida en la larga duración de las transformaciones en los espacios de la vida privada e íntima en Occidente, ${ }^{18}$ que puede resultar o no en una unión. Lo particular en el caso del amor romántico en las sociedades occidentales es el énfasis en la asociación madre-esposa vinculada al cuidado de los hijos y del marido, a unque otros componentes del mismo pueden ser hallados en otras so ciedadesy peńodos históric os. Como lo a dvierten muchos autores, la mujer es el principal actor en este modelo a moroso mistific a do de fusión de los amantes, y en general, se a tribuye más como una cara c terístic a de la construcción de la feminidad desde el siglo XIX. ${ }^{19}$ El papel idealizado del hombre en una relación asimétric a consiste en la protección de la mujer y la prole, garantizando el rol materno de la esposa, aunque las prácticas sociales empíricas conyugales tienden a estar desfasadas del modelo ideal, el cual tiene más un carácter ideológico. 
${ }^{20}$ Ma ra VIVEROSy Willia m CAÑON, 1997; y VIVEROS, 2000a y 2000 b.

21 Bernadette BAWIN-LEG ROS, 2004.

22 BAWIN-LEGROS, 2004, p. 248.

${ }^{23}$ BAWIN-LEG ROS, 2004, p. 248.
Sin embargo, lasmodalida des de subordinación de la mujer van a depender de su inserción en el mercado laboral y, ya en el siglo XX, del sistema escolar, cambiando según las clases sociales. Por esta razón, entramos en la esfera del amor romántico en los distintos sectores sociales para explorar diversas modalidades del afecto.

La ideología del amor romántico en las clases popula res se genera liza, a compañada de los procesos de urba niza ción y modemiza ción en la sociedad colombiana, a partir de 1950 , y sobre todo desde $1970 .{ }^{20}$ En tal sentido, la idealiza ción del sujeto amado y los deseos de fusión de la pareja como mistificación de la relación amorosa, así como el deseo de prolongación en la prole de esa pasión fusional, especialmente a través del ejercicio de la maternidad, ta mbién se ma nifiesta en las c la ses popula res. Esto se puede observarincluso en el auge de lastelenovelas de difusión masiva, que construyen personajes masculinos y femeninos fieles al modelo, procedentes casi siempre de sectores sociales disímiles, quizás en buena parte de los casos con énfasis en el hombre apuesto de clase alta en relación con la mujer joven plebeya. Sin embargo, esa mistificación ideológica pasa en las clases populares por la precariedad de las condiciones de vida. ${ }^{21}$ Para estas clases entonces no pesa tanto un asunto de identificación ideológica delamorni de conservación de la relación de pareja idealizada, aunque en el juego de las manifestaciones de seducción y elección de pareja siga operando el modelo en el ejercicio cotidiano. Las difíciles condiciones de vida pueden incidir para que sean aceptadas uniones en las cuales no hay casi ninguna autonomía de la mujer, especialmente cuando ella en su trayectoria de vida de infante y adolescente ha estado atada a roles domésticos. Como dice Bawin-Legros,

cuando examinamosla escogencia de vida en pareja
y los resultados según nivel educativo (de la mujer),
vemos que es en las categorías donde los individuos
tienen menores oportunidades de educación que el
matrimonio - precedido o no por un período de
cohabitación con la pareja - es más atractivo. ${ }^{22}$

De esta manera, la clase social marca las oportunidades para vivenciar incluso una ligera e improvisada unión. Así, el matrimonio (en su mayor parte como unión libre o llamado concubinato), que extiende los fundamentos de la pareja, y la matemidad (para las mujeres) contribuyen a dirig ir la s expectativa s de las clases populares con escasas posibilidades de escogencia. ${ }^{23}$

Tenemos de este modo una particular articulación de la ideología del amor romántico diferente a la que 
${ }^{24}$ Elvia VARGAS, J ua nita HENAO y Constanza GONZÁLEZ, 2004.

${ }^{25} \mathrm{~J}$ ean-Cla ude KAUFMANN, 1993 y 2003, p. 11.

${ }^{26}$ KAUFMANN, 1993; 2003, p. 11.

${ }^{27}$ CHAUMIER, 2001, p. 46. pudiese darse en las clases medias y altas en la selección de pareja y en la conformación de una unión. Mientras en las clases populares la idealización de la pareja sigue desempeñando un papel, a sí sea en un "mundo de sueños" de los medios de comunic a ción, y la ma temidad constituye la parte más "real" de la relación, la cual a la vezle permite a la adolescente acceder al estatus de mujer, en las otras clases que han acumulado diversos capitales, entre ellos el esc olar y el cultural, la s pa rejas entran a experimenta r el a mor romántico media do cada vez más por una diná mica de autonomización de la mujer y el hombre, con fisuras que pueden transformar la relación. Pero una matemidad atada a la reproducción de roles domésticos requiere de sustento para la madre y la prole. No es casual entonces que en el estudio de Vargas, Henao y González, ${ }^{24}$ sobre historias de vida de mujeres adolescentes, las chicas de sectores populares en las ciudades de Bogotá y Cali en la elección de pareja privilegien fuertemente la figura del hombre proveedor, a diferencia de las adolescentes de c lases medias y altas, pa ra quienes el capital económic 0 del cónyuge es rela tiva mente menos importante, va lorando má s a spec tos rela ciona do s con ca pita les escola ry cultural. En este sentido, la negociación entre losfuturos compañeros se desa rrolla ría por norma implíc itas con dos principios: la equivalencia social y la complementariedad;25 así, en lo concemiente a las cualidades personales, las mujeres de medios populares buscarían un hombre 'trabajador y valiente' mientras que los hombres desea ría n encontra runa mujer 'sencilla y esmerada'. Para Kaufmann, ${ }^{26}$ tanto el hombre como la mujer no se venderían sobre el mercado matrimonial de la misma manera, a pesar de tratarse de un mercado matrimonial paralelo, sino que los pretendientes serían lleva dos a presentarse valorizando los tratos susceptibles de seducir a las personas del sexo opuesto, pero como muestran los estud ios empíric os en las clases populares la pareja hombre proveedor / mujer esmerada (buena madre y esposa) es una modalidad de desarrollo del amor romántico que permite a rticular los proyectos de vida de hombresy mujeres en una idea liza ción conyugal.

Así, a mayor pobreza en las condiciones de vida, en la que sobresale una baja escolaridad y una inserción precaria en el mercado laboral relacionada con la combinación de roles domésticos y una reducida escolaridad, la mujer vive una mayor subordinación respec to a su cónyuge. Como resultado, es un "afecto de necesidad" el que se desarrolla en la relación de pareja por parte de la mujer, sin que medie una propuesta amorosa masculina. Hay que advertir, como lo anota 
${ }^{28}$ KAUFMANN, 1993 y 2003, p. 41.

${ }^{29}$ KAUFMANN, 1993 y 2003, p. 41.

${ }^{30}$ BAWIN-LEG ROS, 2004, p. 248.
Chaumier ${ }^{27}$ que en el amorromántic o para todas las clases sociales, "las mujeres tienen por función amar, lo que explica contrariamente la poca inversión afectiva de los hombres", pero ta mbién que en las clases popula res este fenómeno puede estar más fija do por las condic iones de existencia precaria de la pareja y su prole. Porel contra rio, en las clases medias y altas, pero sobre to do en los grupos sociales con mayor capital escolar y cultural (no necesa riamente de las c la ses domina ntes), las a ltema tivas para la mujer aumentan considerablemente y la relación de pareja pasa por una mayor demanda de inversión amorosa recíproca, al tiempo que una más equitativa distribución de las responsabilidades doméstic as y toma de decisiones fundamentales en el hogar, en un modelo de prole pequeña. De este modo, el amor romántico y el universo erótico-afectivo que lo acompaña no escapan de los constreñimientos sociales, porque como anota Kaufmann ${ }^{28}$ "el amor es una construcción social", en cuanto es el resulta do de un proceso histórico de elaboración de un sentido particular de las emociones entre las personas. Pero es una construcción particular en la que hay siempre un desfase manifiesto entre su representación colectiva idealizada y la manera específica en que cada uno lo vive. ${ }^{29}$

Por otro lado, podría decirse que como ideología poderosa el amor romántico continúa siendo un componente fundamental en la constitución de las relaciones de noviazgo y conyugalidad en las sociedades contemporáneas, incluso en los países capitalistas desa rrollados, no obstante las profundas transforma ciones en las formas de vida en familia, ${ }^{30}$ pero susmanifesta ciones y desarrollos específicos en las maneras de vivir las subjetividades en las trayectorias de vida de las distintas clases sociales presenta ricas variaciones, que deben ser tomadas en cuenta para no caer en un análisis reduccionista. Como veremos más adelante, no es a decua do hacer una genera liza ción para todas las clases populares, ya que ellas son socialmente heterogéneas, y por lo mismo están a tra vesadas por procesos de distinción de acuerdo a las estrategias de acumulación relativa de capita les esc olar, cultural y social, a demás de que muchas veces los individuos de esas clases colocan en juego c a pita les corpora les en el merc a do erótic o que les permite acceder a eventuales uniones con individuos de clases acomodadas. Incluso, también juegan las pequeñas o relativas grandes variaciones de capital patrimonial acumulado en el seno de las clases populares, diferenciando a unos grupos de otros. O sea, la dinámica de clase opera a través de modalidades plurales, en el 
${ }^{31}$ BAWIN-LEG ROS, 2004, p. 248.

32 KAUFMANN, 1993 y 2003, p. 37. interior de los conjuntos o aglomeraciones de un mismo amplio sector social.

Ahora bien, para la producción social del sentimiento a moroso y las mistific a ciones sobre la pareja que idealizan al "príncipe azul" y la "esposa madre fiel al marido y dedicada a sus hijos" en la vida de las personas, el ciclo de vida de la adolescencia y postadolescencia de las sociedades occidentales es una etapa de socialización de las emociones fundamental, curiosamente en la medida en que hoy en día las sociedades contemporáneas son cada vez más exigentes respecto a los procesos de individua ción ${ }^{31}$ sin que ninguna de lasclases socia lespueda estar ausente de este macro proceso. Según Kaufmann,

desde un punto de vista sociológico, el sentimiento a moroso ofrece una paradoja. Se "cae" amoroso, ante todo porque así funciona. De forma tal, que este sentimiento personal se convierte hoy en día cada vez más en el soporte del lazo social. Esto explica el doble carácter de la pareja contemporánea: a la vez más a trayente, más integradora en las relaciones interpersonales, y al mismo tiempo, más precaria, sujeta a serpuesta en duda de un día a otro. ${ }^{32}$

El proceso de subjetivación en progreso cuestiona la ideología romántica, amenazando la estabilidad del orden erótico-afectivo que es todavía dominante, sin que ello conlleve a cambios substanciales en la asimetría de géneros, en la elección de pareja y en las uniones, sobre todo entre las clases populares. Pero, como antes a dvertimos de su heterog eneidad social, quizás en a lgunas capas de estas c la sesya se están presentando interesantes fisuras que avecinan cambios mayores. Por lo que hace referencia a las clases medias esa s fisuras son más visibles y directas.

A nuestro modo de ver las relaciones desigua les de género en sectores populares de Cali asignan los valores tradicionales del amor romántico, y es precisamente ese reforzamiento de tales valores y el papel moral a tribuido a la mujer en dichas condiciones, los que las ponen en condic iones desiguales e inequitativas con respecto a los jóvenes varones. Estos resultados se asemejan a los encontrados para el contexto de la sociedad paulista por parte de Weller. ${ }^{33}$

Los a do lesc entes y posta do lesc entes de los sec tores popula res, o de modo resumido, los jóvenes de esta s cla ses, como categoría resultante de una moratoria social, ${ }^{34}$ son vehículos también de fuertes contradicciones en la producción de afecto y elección de pareja, lo cual se refleja en las trayectorias y los proyectos de vida, y claro, en las identidades subjetivas. Ellos viven la individuación a su 
35 Mujer negra, 19 años, estudiante de educación tecnológica de preescolar, reside con su madre y sus herma nos en el ba mio Charco Azul.

${ }^{36}$ Mujer negra, 27 años, soltera, estudió hasta 90 grado, desempleada, reside en Charco Azul con su hermano y su hijo de 5 años.

${ }^{37}$ URREA y QUINTÍN, 2000.

38 Hombre negro, 17 años, estudió hasta $7^{\circ}$ grado, vive en el bario Charco Azul.

39 Patricia HILL COUNS, 2005. manera, con las implicaciones en el mercado erótico en el interior de las clases populares y entre ellas y las clases medias bajas y medias, para las nuevas cohortes de uniones, aunque como señalaremos más adelante, en el cuadro de los constreñimientos sociales de clase, género y raza.

Distinción en la elección de pareja y mercado erótic o: los desajustes de las cargas de profundida d contra el amor romántico en las clases popula res

Por lo general, las chic as de los sec tores populares, especialmente de los más pauperizados, ya sean o no escola rizadas, atadas o no a los roles domésticos, manifiestan en las entrevistas su desafecto por los chicos de los lugares en donde ellas residen.

Tengo cuatro hermanos... uno es un buen hermano, se graduó de bachillerato, aporta a la casa. El otro trabaja para el solo y no ayuda, el otro es un desempleado y el otro es un niño y no le gusta estudiar... todos los hombres son perros, la mayoría son dañados: ladrones, viciosos, tienen mucha mujer embarazada... (Leidy). ${ }^{35}$

Pareciera expresarse una desvaloración constante que hacen las mujeres de los hombres cercanos a ellas en el espa cio ba rial (sus vec inos, herma nos, novios o a ma ntes, compañeros o pareja). Como dice Pilar, ${ }^{36}$ "....no es fácil conseguir un hombre bueno... (en el barrio)". Por otro lado, en el estudio sobre masculinidades Urrea y Quintín, ${ }^{37}$ ya habían señalado, para el caso de jóvenes de sectores populares en condiciones de exclusión, la percepción creciente de los hombres sobre ciertas mujeres como "igualadas". Fenómeno relacionado con una relativa autonomía de ellasen una serie de esferas de la vida sexual, afectiva, pero también laboral y en la elección de pareja, a sí como en las dec isiones cotidia nas doméstic as y ma nejo del dinero:

hay mujeres que son muy iguala das que quieren hacer lo mismo que uno... esas mujeres así prácticamente no sirven, quieren igualarse al hombre y así no se puede... la mujer debe respetar mucho al hombre (J a ime). ${ }^{38}$

Es bastante factible que una parte de estas mujeres "igualadas", sobre las que recae el rencory las moda lida des de violencia masculina frecuentes, estén en el sistema educativo y allí se destaquen por encima de los compañeros hombresen sus resulta dos escola res, pero a nte todo se distinguen más y más de los antiguos vecinos hombres o hermanos, novios, etc., desertores escolares. Llama la atención que Hill Collins ${ }^{39}$ encuentra una 
40 Marta DOMÍNGUEZ, 1999, p. 24.

${ }^{41}$ Michel AGIER, 1995.

42 Mujer negra, estudiante universitaria, 24 años, trabaja en el área deportiva, soltera y no tiene hijos, vive sola en un barrio de clase media acomodada. Antes vivía con su familia de origen en un barrio popularen el Distrito de Aguablanca, al oriente de la ciudad. representación equivalente de la mujer negra americana producida por la lírica Hip Hop, pero en términos positivos como a firmando una nueva identidad ('get your freak on'), a pesarque este tipo de idea lización de la mujerque rompe con el esquema de subordinación masculina sea estereotipado bajo la modalidad de un objeto sexual.

En este contexto de desvalorización masculina de los hombres del barrio, hay una preferencia por hombres fuera del espacio barrial. Es interesante que la demanda de afecto es común a todas las chicas entrevistadas adolescentes y posta dolescentes -, ya sea en el contexto de una pareja idealizada en la que el hombre esel principal proveedor (y este factor es más importante que el amor romántico en las clases populares), o en el de una pareja cercana al modelo reflexivo de lasclases medias, en donde el cariño y la temura, además del sexo, juegan un papel preponderante. Sin embargo, son las mujeres esc ola riza das quienes tienen las mayores opciones de circulación e intera c ción c on hombres de otros sec tores sociales, a tra vés del espacio escolar y otros espacios colaterales a éste. Esto no quiere decir que las mujeres no escolarizadas no intenten también escapar a la vida barrial, ya que, como lo muestra Domínguez, ${ }^{40}$ en general las mujeres jóvenes de sectores populares, independientemente de su capital escolar, son más cosmopolitas urbanas, mientras los hombres se caracterizan por estar más fincados en el territorio barrial a través del grupo de pares. Cuando una mujer está cerca o pertenece a una pandilla, su distanciamiento y salida no se asocia a la dificultad de encontrar al hombre adecuado, sino con salir del barrio. Esto coincide con los hallazg os de otros investiga do res que detectan esta lógica de circula ción de las mujeres de todas las edades hacia el exterior del barrio y moviéndose en muchos espacios de la ciudad, ${ }^{41}$ a diferencia de lo que sucede con los hombres de los sectores populares.

Este patrón diferenciado de comportamiento por género, en el que las mujeres desa rrollan estra tegias para escapar del espacio doméstico y sus constreñimientos, produce fisuras en las a simetrías de género, que desestabilizan el mercado erótico entre las clases populares, especialmente en las áreas de urbanización precaria. Claudia, ${ }^{42}$ una persona con capitales escolar, cultural y social, es un caso que ilustra la lógica en que opera esta situación:

... normalmente ha sido como la característica buscar personas como de un cierto nivel sociocultural y aca démic 0 , al mismo nivel que el mío, si básicamente si van a ser digamos compañeros o si se van a relacionar conmigo ... yo creo que siempre y cuando 
las personas estén libres de prejuicios y de mitos y de cosas yo creo que eso no tiene porque afectarla forma en que se relacionen ... siempre he preferido, me han gustado los hombres blancos y si son negros, pues por lo menos que sean a mi parecer atractivos, pero básicamente si, afectivamente y sexualmente me he relacionado más con hombres blancos. Yo creo que prefiero a los hombres blancos...Porque (ńe) la cuestión es también que ... normalmente el hombre negro o las personas negras de pronto no tienen un nivel socioec onómic o o cultural de pronto a corde con lo que yo estoy buscando, puede ser, porque igual hay muchos hombresnegros que tienen su nivel ec onómic 0 alto y toda la cosa y eso lo hace ver como un hombre interesante, si yo creo que es como por esa cuestión, por las menos posibilidades de encontrar un hombre negro con un esta tus económic o y cultural a lto o medio ... yo creo que encontrando un hombre negro con esas condiciones sería diferente, o sea, eso es básicamente lo que yo busco, no de pronto que sea negro o no, sino de que sea negro o blanco, tenga esa posibilidad de tener un estatus.

En esta dirección entonces los jóvenes con los más bajos capitales escolar y cultural, son menos desea dos en la elección de pareja para el noviazgo o una eventual unión por las mujeres escolarizadas. El resultado es que la competencia porlasmujeresque se mantienen en el barrio, o sea, las que también tienen los menores capital escolary cultural y están más a tadas a los roles domésticos se incrementa. Debido a la marginalidad en las trayectorias de vida de los chic os desesc ola riza dos con una a ltemancia cada vez más frec uente en actividadesilíc itas de a lto riesgo, con el resultado de una alta mortalidad por muertes violentas, las posibles uniones no tienen mucha duración y la viudezcon prole forma parte de la vida temprana adulta de muchas chicas.

Las mujeresnegras de sectorespopula reso de clases mediasbajas en proceso de ascenso vía capital escolary cultural, enfrentan situaciones de exclusión por

${ }^{43}$ QUINTÍN, RAMÍREZ Y URREA, 2000. discriminación racial. ${ }^{43}$ Debido a este factortienen menos posibilida des de ser exitosa s en el merc a do erótico de otros sectores sociales más a comodados, especialmente mestizos y blancos, a diferencia de las mujeres mulatas. Entre otras, porque los estereotipos discrimina torios sobre sus capacidades amatorias de parte de la población mestiza y blanca, son un handicap en lugar de un a tributo favorable, en el sentido que la aspiración de relaciones amorosas menos desiguales frente a los hombres choca con una dura realidad, según Claudia, 
44 Planificación Familiar Salud y Reproductiva, entidad privada que lidera los programas de SSR en el país, especialmente entre población joven.

${ }^{45}$ La muestra de cinco colegios en el oriente de la ciudad con alumnos de sectores populares y clases medias bajas fue de 252 estudiantes, 144 mujeres y 108 hombres. La muestra en la Universidad del Valle fue de 117 estudiantes, 59 mujeres y 58 hombres.
... una cosa que está marcada es que la mujer negra (tiene) un bonito cuerpo ... que unas caderas anchas, unos glúteos muy voluptuosos, es una mujer que es muy caliente, que por naturaleza es muy caliente, entonces eso se asocia a que debe ser muy buena en la cama y que debe proporcionar mucho placer, pero yo creo que eso es más del imaginario de la gente, porque no necesariamente depende eso (ser buena en la cama) de su color, yo creo que tiene que ver más factores culturales, educativos...

Por este motivo pueden ser deseadas más como sujetos de placer instrumental que como sujetos a morosos. Este es un reclamo genera liza do que aflora en la sentrevistas a las mujeres negras, adolescentes de colegios de secundaria y postadolescentes universitarias.

El resulta do puede significarcon frecuencia posponer el ejercicio de la sexualidad para las mujeres negras escolarizadas. Esto significa que quizás una parte de ellas no entran en el mercado erótico de los otros sectores sociales con predominio de hombres blancos y mestizos, a unque tampoco en el que concurren los hombres negros. En dos encuestas que aplicamos entre diciembre de 2003 y febrero de 2004, una rea liza da con estudiantes mujeres y hombres, entre 10 y 17 años, en colegios de secundaria del oriente de la ciudad, y otra llevada a cabo en la Universidad del Valle con estudiantes entre 18 y 26 años, ambas sobre prácticas de sexualidad y su interacción con los programas de SSR de la entidad Profamilia ${ }^{44}$ en colegios y el Servicio de Salud Universitario en Univalle, ${ }^{45}$ las chicas negras en ambos contextos sistemátic amente tienen una edad de iniciación sexual en promedio por encima de las mujeres mestizas y blancas, independ ientemente al estra to socioeconómico. Las adolescentes negras en los colegios con 16.11 años de promedio y 16 años de mediana; las mestizas c on 15.0 años de promedio y las blancascon 14.9 años (y las dos últimas con una mediana igual de 15 años). En la universidad pública los datos son: 18.0 años para las chicas negras de promedio y 17 años de mediana; 16.38 años de promedio para las chicas mestizas y blancas y una mediana de 16 años para las dos. Lo anterior se corresponde con un número de mujeres escolarizadas negras de colegio y universidad que en el momento de la encuesta aún no había tenido rela ciones sexuales genitales, el cual es bien superioral de las mujeres blancas. Sola mente en el colegio las mujeres negras y mestizas presentan un número similar de relaciones sexuales por debajo de las blancas. En cambio, en la universidad también se diferencian de las mujeres mestizas, con un menor número de chicas negras iniciadas sexualmente. 
46 Mujer negra, estudiante universitaria, 23 años, soltera, comparte a partamento con unos a migos en el barrio Cañaverales, dicta clases de ingles en un instituto.
${ }^{47}$ Como se ha observado en varios estudios el grupo de pares masculino en las clases populares está fuertemente adscrito al manejo de temitorios intrabamiales. Opera como parte de los mecanismos masculinos de dominación sobre lasmujeresy los mismoshombres. En general, en él sus participantes desarrollan conducta shipemasculina sexistas y homofóbic as (URREA, 2002). 48 URREA y QUINTíN, 2002; y URREA, CONGOUNO, y HERRERA, 2003.

49 Hombre negro, estudiante universita rio, 23 años, sin hijos, vive con unos familiares.
La renuncia al ejercic io de la sexualidad lo manifiesta Juana, ${ }^{46}$ quien a favor de su desarrollo profesional ha aplazado todo tipo de encuentro sexual:

ahí -ahora- no tengo ni siquiera la concepción de decir, es que estoy esperando a alguien muy especial para hacerlo, sino que como yo hice una promesa para teminar mis estudios, yo le hice una promesa a Dios, entonces a partir de eso. Así, es que voy a durar virgen hasta este año ... pero a hora créeme yo hice la promesa y más se me alborotan las hormonas y ahí es que yo digo, yo para qué lo hice...como yo le dije a un ex novio antes, no la rompo, no porque no quiera sino porque yo se la hice a Dios. Yo la promesa se la hubiese hecho a un novio o a un serhumano, pues yo digo qué ¡carajo! Igual vamos a pasarla rico, pero yo se la hice a Diosy la promesa que yo le hago a Dioses sagrada...

Es indiscutible que los datos precedentes posiblemente conllevan un retardo a la entrada en unión de estas mujeres negras escolarizadas procedentes de sectores populares y cla ses medias bajas, a demás que su elección de pareja tampoco necesariamente se da en forma exitosa con jóvenes de clases medias mestizos o blancos. Es decir, entra en juego de alguna forma el fenómeno de la homogamia social y racial, incluso para las chicas negras que vienen de sectores populares en proceso de movilidad social ascendente a través de ganancias en capital escolary cultural.

El amor romántico en las clases populares, por lo tanto, también enfrenta una dinámica de erosión, especialmente a través de las mujeres escolarizadas que salen del merc a do erótic o intra ba rria l, al igual que a lgunos hombres que logran mantenerse en el sistema escolar y que por lo mismo alcanzan a escapar de la lógica del grup o de pares, ${ }^{47}$ el factor más conservador y reproductor de la ideología del amor romántico en su versión más asimétric a y de subordinación para las mujeres y los hombres que buscan nuevas formas alternativas de masculinidad. ${ }^{48}$

Por el lado de los hombres negros, estudiantes universitarios, a pa rece entre los entrevista dosuna queja similar a la de las mujeres. Manifiestan que sus compañeros de estudio mujeres y hombres, mestizos y blancos, los clasifican bajo estereotipos sexuales asociados al color de piel. En los interc a mbios erótic os con mujeres no negras predomina una interacción sin un envolvimiento amoroso-afectivo que termine en la elección de pareja. Como dice Charlie, ${ }^{49}$

... porlo menosahora tengo rabia con eso, porlo menos en el caso mío, yo no soy un man frío, o sea, no soy un cuerpito, un pipícon piemasque anda porahí, no soy 
50 Transgredir las fronteras de la homogamia racial y socioeconómica, mediante una unión que signifique para uno de los cónyuges el reclasamiento o lo contra rio, el desclasamiento.

51 Jorge A. GAMBOA, 2003; y Pablo RODRÍG UEZ, 2004.

52 Hombre mestizo, estudiante universitario, 24 años, soltero sin hijos, quien vive con sus padres en el barrio Nueva Base, sector de clase media baja del centrooriente de la ciudad.

53 "Monas": mujeres rubias o muy blancas. solamente sexo, pero de todas formas el indicador del tono de piel siempre va a estarmás relaciona do al sexo; por ejemplo, vos en una rumba te miran y no te quieren para darte un besito. ¡Ay! ¡Tan lindo el negrito! ¡No! Me quieren es comer, te quieren es comer, eso sí es de a hí. $Y$ te hacen propuestaso son insinua ntes con el cuerpo.

Este tipo de interacción personal no favorece la elección de pareja interracial y más bien aumenta las posibilidades de una elección recíproca homogámica entre hombres y mujeres negros-as.

Sin embargo, en el juego de los estereotipos raciales en la esfera de la sexualidad, no puede caerse en una visión simp lific a dora en la que los hombres y mujeres negrosas son agentes pasivos en un espacio de jerarquía racial desigual. A su vez, ellos ponen a disposición esos estereotipos, haciendo de los mismos una inversión favorable en el mercado erótic o frente a mujeres y hombres mestizos y blancos. Los estereotipos se convierten así en armas de seducción poderosas de conquista, asociados como capital corporal naturalizado. El personaje anterior, Charlie, en sus respuesta s a mbiva lentes parece aceptar el juego, usánd olo a su favor en sus intercambios con chicas no negras. Pero como se verá, a través de algunas estadísticas disponibles más adelante, hay una clara diferencia entre negrosy mula tos, tanto para hombrescomo mujeres, de modo que los mulatos-as tienen mejores opciones de ascenso social a través de las uniones con blancos-as y mestizos-as, lo que muestra que el efecto de la hipergamia ${ }^{50}$ está más vinculado a la ideología del mestizaje.

Por lo anterior, es preciso introducir el papel del mestizaje a través de la mulata y el mula to en una ciudad como Cali y otras regiones del país, el cual ya ha sido señalado por historiadores como Gamboa y Rodríguez, ${ }^{51}$ a lo largo de los siglos XVIII y XIX. Su importancia en la historia de las representaciones cotidianas de los cuerpos oscuros sin ser completamente negros, forma parte del imag inario colectivo caleño y su relación con la elección de pareja y las mezc las interracialesen las uniones. Andrés ${ }^{52}$ es un universitario que se expresa así:

... lastípicas mona ${ }^{53}$, de hecho a mi no me gustan, no me llaman la atención tanto y las bien blanquitas tampoco. Que tenga buen rabo, eso me parece muy chévere, que sea trigueñita. ¡Como mulata!

Sin embargo, a pesardel impacto de la mula ta y el mula to en las interacciones cotidianas, es un hecho que la figura de la mujer y hombre negro están igualmente asociadas a la vida de la ciudad. Un buen ejemplo lo 
54 Véa se URREA, 1997, p.155; y URREA, 2000, p. 30-35.

55 Nieves, mujer negra tiene un compañero hombre negro. constituye la caricatura de Nieves, publicada en el dia rio más importante de la región, El País, desde hace 30 años, donde son típicamente representados, a través de dos personajes, los oficios de "negros" en la región. En la caricatura, 'Nieves' es la sirvienta negra y su compañero, 'Hétor', obrero de la construcción. Los dos corresponden a personajes ingenuoscon baja escolaridad, que se atreven a opinar o "filosofar" sobre temas de la vida cotidiana y acontecimientos sociales y políticos a partir de frases de sentido común con las cuales generan reacciones de sorpresa por su ingenuidad y visión simplista de la vida. ${ }^{54}$ No obstante su popularidad muy polémica, el valor simbólico de estos dospersonajes en Cali conserva mucha ambigüedad, llegando en ciertos contextos a invertirse el estigma, para usarlos como figuras de 'identidad negra' en lossectorespopula res. Podría entoncesconsidera rse una ambivalencia en las representaciones colectivas urbanas entre las figuras fenotípicas de gente negra versus las de gente mulata. Las primeras como parte de un mundo "exótico" aparte, ${ }^{55}$ bajo la denominación local y regional de "niches" (gente fenotípicamente negra), mientras las segundas formando parte de un mundo integrado y aceptado, lo que significa una alta valoración positiva del mulato y la mulata, bajo la denominación émica de "trigueño oscuro". Veremos más adelante cómo esta ambivalencia tiene un interesante efecto diferenciado en la homogamia racial, si se trata de uniones con jefe de hogar y cónyuge negro o mulato.

\section{El efecto combinado de clase, raza y género en las uniones de Cali}

Los direccionamientos que hemos previamente traza do a partir de da tos cua lita tivos respec to a las lógicas del amor romántico y las formas del afecto, entre la población adolescente y postadolescente de las clases populares, una parte de ella en condiciones de exclusión social, a rroja n entre los resulta dos, a demás de losconflic tos y fisuras de género, desbalances en el mercado erótico y de uniones en estas clases. Este proceso es un complejo y rico espacio afectivo de sociabilidades y de producción de la conyugalidad que no puede verse separado de los constreñimientos de clase social, raza y género en una sociedad urbana mestiza como la caleña. Los datos cuantitativos sobre tasas de homogamia racial en las uniones, que se presentan a continuación, ayudan a entender mejor las determina ciones sociales en las que se mueven los deseos, los afectos, y el mercado erótic o y el de uniones entre la gente negra-mulata y blanca-mestiza 
${ }^{56}$ Ala in G IRARD, 1964.

${ }^{57} \mathrm{~J}$ ean KEUERHALS etal., 1993, p. 23.

${ }^{58}$ KEUERHALS et al., 1993, p. 24.

${ }^{59} \mathrm{Como}$ un indicador proxy a la menor o mayor mezcla racial en la esfera de la conyugalidad, a partir de los datos estadísticos disponibles.

${ }^{60}$ En términos émic os la expresión mulato hace referencia a la mezcla racial blanco/negro en to das sus moda lida des y mestizo a la blanco/indígena, en el contexto de los países andinos. Sin embargo, también es frecuente la mezcla indígena/negro (término zambo), pero para efectos de la connotación émica puede caer como negro o mulato, dependiendo de la mayoro menorosc uridad de piel.

${ }^{61}$ Se toma como indicadorproxy (bien grosero) para la clase el de quintiles de ingreso. de la ciudad. Girard, ${ }^{56}$ cita do por Kellerhals et al., ${ }^{57}$ define la homogamia como el hecho de desposar a alguien parecido socialmente. Esta proximidad puede darse en términos geográficos, generacionales, sociales, étnicoraciales y culturales. Para esta ponencia, se pretendió profundizar específic amente sobre la homogamia racial y la relación que ésta podría guardarcon la clase social y el género en el caso colombiano. En consecuencia, la tendencia de los individuosa preferir unirse con sus iguales sobre la escala de las clases sociales. ${ }^{58}$

La Tabla 1 permite observar una homogamia racial para los hogares con cónyuge presente en el conjunto de la ciudad de Cali, en el año 1999, similarpara la población negra y blanca, en relación con el color de piel de los jefes de hogar de los cónyuges (porcentajes horizontales), de alrededor $88 \%$. Son los dosgruposracialescon la mayor homogamia referida a la pareja jefe/cónyuge del hogar en la ciudad. ${ }^{59}$ Por el contrario, la población clasificada como mulata a rroja la menortasa de homogamia (75.6\%), seguida de la mestiza (81.7\%). Este fenómeno de una menor homogamia en los mulatos, seguidos de los mestizos, se acomoda aparentemente bien a la imagen de ciudad mestiza "trigueña", entre colores má soscuros a más cla ros, como antes se advirtió. ${ }^{60}$

Al a na lizar los datos por quintiles de ingreso de los hogares se tiene que la homogamia es mucho másalta en la población negra del primer quintil de ingresos (tasa de $94.3 \%$ ), disminuyendo sobre todo en los quintiles cuarto y quinto (desciende a $83.0 \%$ ), con un ligero repunte en el tercerquintil. En el caso de la población mula ta se observa la misma tendencia, con un repunte en el cuarto quintil. En la mestiza los datos son más erráticos, lo cual indic a ría que no presenta una tendencia específica, a unque es cla ro que en los dos quintiles superiores a rroja un descenso significativo de la homogamia sin llegar al caso de la mulata. Finalmente, en la población blanca se registra un patrón muy constante en las tasas de homogamia, independientemente del quintil de ingresos. En conclusión, para la gente negra y mulata sí parece operar un efecto de clase, ${ }^{61}$ en el sentido que los sectores populares negros de menores ingresos tienden a reproducir mayores condic iones de homogamia racial en la esfera conyugal y a medida que se asciende socialmente tiende a darse un efecto de aumento de las mezclas raciales (menor homogamia), sin que tampoco pueda considerarse que operen tasas inferiores al $40 \%$ (sobre to do para los jefes de hogarmulatos en el quinto quintil); lo cual quiere decir que el efecto social de la homogamia racial opera a lo largo de las desigualdades de clase, pero en sentido de su 
${ }^{62}$ KAUFMANN, 1993 y 2003, p. 6.

${ }^{63}$ Elza BERQUÓ, 1987, p. 44.

${ }^{64}$ BARBARY Y URREA, 2004; Lilia MORITZSC HWARCZ, 1998; y Peter WADE, 1997b. descenso para determinadosgrupos raciales. Un fenómeno distinto se presenta para la población blanca al estar presente con distribuciones constantes que no marcan una tendencia clara por clase social en sus uniones: alta homogamia para la gente blanca en todos los quintiles. En la población mestiza con un patrón errático de todas manerasindica una mayorhomogamia en los tres primeros quintiles, o sea, en los que agrupan a las clases populares y clases medias. A diferencia de Ka ufmann, ${ }^{62}$ quien señala que la homogamia tiende a sermás fuerte en los extremos de la escala social, la particularidad del hallazgo en el caso de la ciudad de Cali es una segregación por color de piel en todas las escalas sociales de la gente blanca (alta homogamia), mientrasla población no blanca - negra, mulata y mestiza - tiende a una mayor homogamia en los grupos de menores ingresos, disminuyendo a medida que aumenta el ingreso. Sin embargo, este fenómeno de disminución, como ya se advirtió, es mucho más marcado para los mulatos y los mestizos.

Un fenómeno similar se presenta en la sociedad brasileña. Elza Berquó ${ }^{63}$ advierte que la mayor parte de las uniones en Brasil son endogámicas en términos raciales, alrededor del 79\%. La población blanca, al igual que los da tos para Cali, es má shomogámica y del mismo modo el mestizaje va en aumento a través de la población equivalente a la mulata, la parda (menos homogamia o mayor hipergamia). Esto seguramente tiene que ver con patrones de discrimina ción racial muy simila res en las dos sociedades, la brasileña y la colombiana. ${ }^{64}$ 
Tabla 1 - Homogamia de los hogares completos (nucleares, extensos y compuestos), según CARAC terístic AS RACiales del J EFe de hogar y Cónyuge, para Cal (Septiembre 1999)

Características raciales del jefe de hogar

\begin{tabular}{|c|c|c|c|c|c|c|c|c|c|c|c|}
\hline \multicolumn{2}{|c|}{$\begin{array}{l}\text { Características } \\
\text { raciales del } \\
\text { cónyuge }\end{array}$} & $\begin{array}{l}\text { Negro } \\
\text { Obs. }\end{array}$ & $\%$ & Obs. & la to & Obs. & stizo & \multicolumn{2}{|c|}{ Blanco } & Total & $\%$ \\
\hline \multirow{4}{*}{$\begin{array}{c}\overline{\bar{D}} \\
\overline{\bar{z}} \\
\overline{\mathrm{O}}\end{array}$} & Negro & 6030 & 94.3 & & & & & & & 6396 & 100.0 \\
\hline & Mula to & & & 10575 & 81.5 & & & & & 12980 & 100.0 \\
\hline & Mestizo & & & & & 6983 & 83.8 & & & 8334 & 100.0 \\
\hline & Blanco & & & & & & & 18508 & 88.2 & 20981 & 100.0 \\
\hline \multirow{4}{*}{ 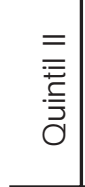 } & Negro & 7343 & 88.0 & & & & & & & 8342 & 100.0 \\
\hline & Mula to & & & 10735 & 79.4 & & & & & 13514 & 100.0 \\
\hline & Mestizo & & & & & 12835 & 86.8 & & & 14793 & 100.0 \\
\hline & Blanco & & & & & & & 20820 & 86.4 & 24086 & 100.0 \\
\hline \multirow{4}{*}{$\begin{array}{l}\equiv \\
\overline{\overline{7}} \\
\cdot \overline{\bar{z}} \\
\bar{\sigma}\end{array}$} & Negro & 5602 & 91.2 & & & & & & & 6145 & 100.0 \\
\hline & Mula to & & & 8904 & 69.8 & & & & & 12765 & 100.0 \\
\hline & Mestizo & & & & & 11833 & 81.3 & & & 14551 & 100.0 \\
\hline & Blanco & & & & & & & 21433 & 88.9 & 24096 & 100.0 \\
\hline \multirow{4}{*}{$\begin{array}{l}\geq \\
\frac{1}{2} \\
\frac{1}{3} \\
0\end{array}$} & Negro & 2798 & 81.2 & & & & & & & 3447 & 100.0 \\
\hline & Mula to & & & 5906 & 76.0 & & & & & 7772 & 100.0 \\
\hline & Mestizo & & & & & 9809 & 78.3 & & & 12533 & 100.0 \\
\hline & Blanco & & & & & & & 26725 & 87.4 & 30578 & 100.0 \\
\hline \multirow{4}{*}{$\begin{array}{l}\text { Dे } \\
\text { 产 } \\
\text { 言 }\end{array}$} & Negro & 5459 & 83.0 & & & & & & & 6577 & 100.0 \\
\hline & Mula to & & & 2753 & 63.1 & & & & & 4362 & 100.0 \\
\hline & Mestizo & & & & & 7938 & 77.6 & & & 10230 & 100.0 \\
\hline & Blanco & & & & & & & 21346 & 87.6 & 24364 & 100.0 \\
\hline \multirow{4}{*}{$\begin{array}{l}\overline{9} \\
\stackrel{0}{0}\end{array}$} & Negro & 27232 & 88.1 & & & & & & & 30907 & 100.0 \\
\hline & Mula to & & & 38873 & 75.6 & & & & & 51393 & 100.0 \\
\hline & Mestizo & & & & & 49398 & 81.7 & & & 60441 & 100.0 \\
\hline & Blanco & & & & & & & 108832 & 87.7 & 124105 & 100.0 \\
\hline
\end{tabular}

FUENTE: Encuesta Banco Mundial-Cidse/Univalle, Septiembre 1999. Procesamiento especial de los hogares completos (con jefe de hogar y cónyuge; ya sean nucleares, extensos o compuestos), fueron excluidos los hogares unipersonales, monoparentales (nucleares, extensos y compuestos) y los colec tivos. Únic amente se dejaron los porcentajes fila que permitan observar en forma clara la matriz. 
${ }^{65}$ WADE, 1997a y $1997 \mathrm{~b}$.

${ }^{66}$ BARBARY Y URREA, 2004.

${ }^{67}$ Lastasaspara losjefes de hogar mulatos en esos dos quintiles respectivos son 66.6 y 42.2 , mientras sus cónyuges tienen tasas de 76.0 y 63.1 .

${ }^{68}$ SING LY, 1993.
Retomando los datos para el conjunto de la ciudad, la mayor homogamia de la población negra se explica por tasas superiores en los quintiles de menores ingresos (del primero al tercero), mientras que para la población b lanca las tasas muy simila res en tod os los quintiles revelan una estrategia de reducción de la mezcla racial tanto en los sectores populares como en las clases medias y altas. Porel contra rio, la gente negra, mula ta e incluso la mestiza desarrollan estrategias de ascenso social en sus uniones, las cuales debido al carácter de la jerarquía racializada en la sociedad colombiana se expresan como formas de "blanqueamiento", fenómeno ya advertido por Wade ${ }^{65}$ y Barbary y Urrea. ${ }^{66}$ En este juego es posible que al lado de los menores capitales acumulados históricamente por la gente negra, sobre todo escolar y cultural en el caso de los hombres, el capital corporal mediante la capacidad seduc tora del colorde piel, al lado de otrosa tra ctivos físic os, desempeñe un papel importante en la negociación en el mercado erótico para mujeres y hombres, mulatos-as, negros-as y mestizos-as.

Sin embargo, este fenómeno de menorhomogamia (o lo contra rio, pa trones de hipergamia) es definitiva mente predominante en el caso de la población mulata y en cambio más reducida para la población negra, como se puede observaren la Tabla 1. Además, los jefes de hogar mulatos presentan tasas mucho más reducidas de homogamia que sus cónyuges del mismo grupo racial en los quintiles cuarto y quinto ${ }^{67}$ El mula taje, como moda lidad de mestizaje, cobra así una especial a tención en el caso de la ciudad de Cali en cuanto vehículo de movilidad social, según lo señalamos previamente. Pero según se advirtió antes, incluso en el caso de los jefes de hogar mulatos cuya tasa menor de homogamia en el quintil de ingresos superior está ligeramente por encima de $40 \%$, los constreñimientos sociales operan en el mercado erótico de elección de pareja, de manera que se reproduce la jera rquía social racializa da en las uniones de la ciudad.

De Singly ${ }^{68}$ señala que el 'c apital femenino' vendible reposa sobre su físico y su carácter, mientras el 'capital masculino' sobre su excelencia social, correspondiendo a un cierto grado de 'capital femenino' el mismo grado de 'c apital masculino', lo cual favorecería la heterogamia en la medida en que los capitales intercambiables tuviesen un valor equivalente a los ojos de los actores. Pero hay que a dvertir que en el ca so observa do es especia Imente vá lido para las mujeres mula tas y mestiza s cónyuges, mientras en las mujeres negras es menor y no parece darse en las mujeres blancas. Es decir, la hipergamia como estrategia de movilidad social pasa pordetermina doscoloresde piel, 
${ }^{69}$ KELERHALS el al., 1984, p. 25.

70 QUINTÍN, RAMÍREZ y URREA, 2000.

${ }^{71}$ La encuesta permite además diferenciara la población que se autoreconoce como indígena y gitana, pero por razones de su escaso peso en el tamaño de la muestra la excluimos del a nálisis. Véase Cidse-Univalle, Informe Final ECV 2003 para el Valle del Cauca (2004).

Desafortunadamente los datos disponibles se agrupan en dos grupossin matic es: negro-mulato y mestizo-blanco. mientras la homogamia tiende a ser constante en el caso de lasmujeres blancascónyugesal controlarla cla se social. Sin embargo, hay que señalar que los hombres mulatos y negros ponen en disposición su capital corporal, comportándose de manera semejante a las mujeres, ya sea para intercambios heterosexuales como homosexuales con mujeres y hombres mestizos y blancos. En tal sentido, sería válida la expresión de "capital masculino" en los nuevos contextos de elección de pareja; y si los datos indican que los hombres mulatos jefes de hogar en los niveles de ingresos más altos presentan una mayor hipergamia que las cónyuges mujeres, es posible que en esta situa c ión esté en juego, a demás de ca pita l económico y escolar, un capital corporal.

Por otro lado, la unión como mecanismo visible de "bla nquea miento", a so cia do al a scenso social, se a proxima al análisis de Kellerhals et al. ${ }^{69}$ respecto a que los actores buscan conservar o a umentar sus capitales materiales o simbólicos, que en el caso colombiano pasa por el color de piel. Esto es válido en el plano simbólic o corporal. Ya en otro estudio de Quintín, Ramírez y Urrea ${ }^{70}$ se concluye que las clases sociales en la sociedad colombiana tienen color de piel.

Las Tablas 2 y 3 registran una información recogida a tra vés de la Encuesta de Calidad de Vida 2003 del Da ne, en la cual se incluyó una pregunta de auto-reconoc imiento étnic o-racial: negro o mula to (y otra s ca teg oría s regiona les para designa rétnica mente la gente negra) versus sin ningún auto-reconocimiento étnico-racial (en efecto incluimos genéricamente mestiza o blanca). ${ }^{71}$ Los datos muestrales permiten desagregar solamente para la región urbana del Valle del Cauca, cuya capital es la ciudad de Cali. No obstante, Cali representa aproximadamente el $65 \%$ del tamaño de la muestra de la región (Informe Final CidseECV de 2003, 2004), por lo que hemos considerado adecuado tomar la información de esta encuesta equivalente para la ciudad. La Tabla 2 , hace referencia al comportamiento de la homogamia según quintiles de ingreso, con la advertencia que, debido a problemas de tamaño de muestra (con efectos de error de muestreo), se agregaron los quintiles cuarto y quinto; en la Tabla 3, a la homogamia portres grandes grupos de edad del jefe de hogary por los dos grupos "raciales".

En la Tabla 2, a pesar de la reducción entre dos grupos "étnico-raciales", muestra los diferenciales de homogamia según sea el jefe del hogar (porcentajes por columna) o el cónyuge (porcenta jesporfila). Para la región del Valle un poco más del $93 \%$ de los jefes de hogares nucleares, extensos y compuestos que tienen cónyuges son 
hombres, en tal sentid o es posible advertir que en este caso los hombres jefes presentan estrategias diferenciales respecto a los cónyuges mujeres en términos de homogamia racial, según el grupo "étnico-racial".

TABLA 2 - Homogamia de los hogares completos (NUCLEARES, EXTENSOS Y COMPUESTOS), SEgúN CARACTERÍSTICAS RAC IALES DEL J EFE DE HOGAR Y CÓNYUGE, POR QUINTILES DE INGRESO, PARA EL VALLE URBANO (JUNIO 2003)

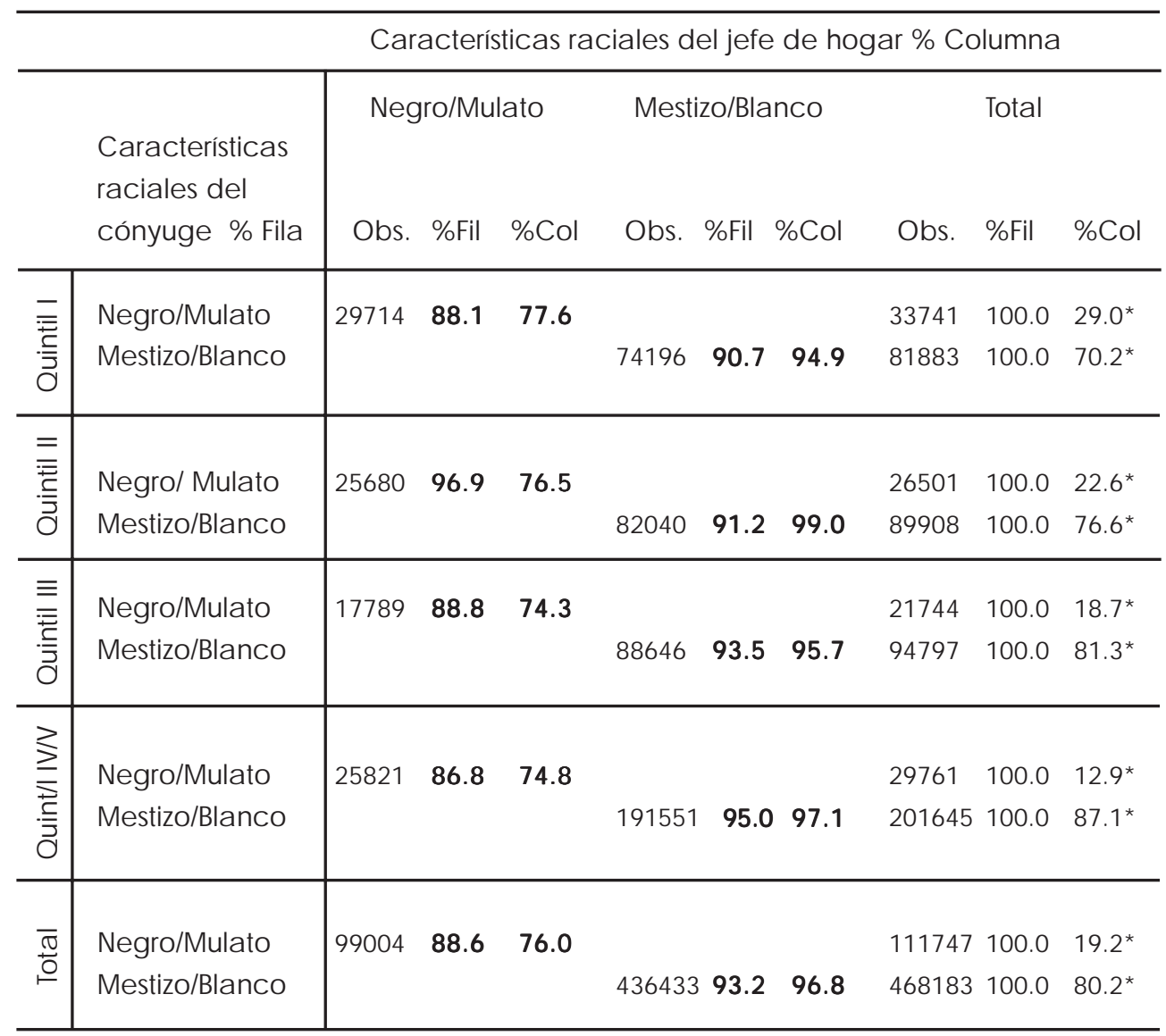

FUENTE: Grupo de investiga ción sobre pobreza y desigualdad, 2004. Procesamiento especial de la Encuesta de Calidad de Vida, Dane, junio de 2003. Se incluyeron solamente los hogares completos (con jefe de hogary cónyuge; ya sean nucleares, extensos o compuestos), fueron excluidos los hoga res unipersonales, monoparentales (nucleares, extensos y compuestos) y los colec tivos.

* Los porcentajes de columna para el total en los quintiles I y II no dan $100.0 \%$ debido a que faltan los valores pequeños de la población indígena y gitana, que ha sido excluida de este a nálisis por los reducidos tamaños de muestra. Igualmente sucede con el total de observaciones debido a ese reducido faltante. Únic amente se dejaron los porcentajes de fila y columna que permitan observar en forma clara la matriz. 
72 Al agregar los datos del total de la Tabla 1, de población negra y mulata por una parte, y los de mestiza, indígena y blanca, por otra, para efectos de hacerlos comparables con los de la tabla 2, se tiene que en 1999 para Cali, la tasa de homogamia de la población negra/mulata en cónyuges (porcentaje fila) era 82.9 y en jefes de hogar (porcentaje columna), 81.5. La población mestiza/blanca (incluyendo indígenas) tenía respectivamente 91.9 y 92.6. No puede inferirse una tendencia de incremento de tasas entre los dos tipos de datos, ya que la metodología de las dos encuestas es muy diferente: la encuesta Cidse-Banco Mundial se basa en una clasificación fenotípica extema por parte del encuestador, mientras la ECV 2003 se apoya en un autoreconocimiento "étnico-racial" porparte del miembro del hogar que responde la encuesta, a la vezde una clasificación que hace éste de los otros miembros del hogar. No obstante esa importante diferencia, ambos datos tienden a mostrar tasas cercanas de alta homogamia, siendo superiores las de la población mestiza/blanca en ambas encuestas. Los diferenciales por género (cónyuge versus jefe de hogar) en cambio no son tan fuertes en la encuesta Cidse-Banco Mundial, si bien mantienen la misma tendencia que los de la ECV 2003.
Para el conjunto del Valle urbano, en donde Cali representa el $65 \%$ de los hogares y un poco más del $60 \%$ de la población urbana, hay un comporta miento inverso: en la población negra/mulata los jefes arrojan una menor tasa de homogamia mientras las cónyuges una superior; fenómeno opuesto en la población mestiza/blanca, ya que aquí es al revés, los jefes tienen una tasa superior de homogamia (bastante alta, del $96.8 \%$ versus $93.2 \%$ de las cónyuges). Por otro lado, al tomar agregadamente los grupos "étnico-raciales" en forma bipolar, definitivamente la población mestiza/blanca registra una tendencia más homogámica. Si relacionamos estos datos con los de la Tabla 1, indiscutiblemente es el efecto de la población mulata en el primergrupo y de la blanca en el segundo..$^{72}$

Ahora bien, por quintiles de ing reso son los jefes de hogar en la población negra/mulata los que tienen un patrón de descenso relativo de la homogamia a medida que aumenta el nivel de ingresos, mientras las cónyuges no tienen ese comporta miento, ya que es más bien errátic 0 .

Este comporta miento de los da tos nos permite sugerir la siguiente hipótesis complementaria a las del análisis de la Tabla 1, pero advirtiendo del efecto en la agregación de los mula tos-as y mestizos-as en la Tabla 2: en forma conjunta los datos del 2003 vuelven a reg istrarque la gente mestiza/blanca desarrolla estrategias sociales de mayor homogamia racial, especialmente en el caso de las cónyuges, mientras para la gente negra/mulata las estra tegias de menor homogamia son más orientadas por los jefes de hogar, en su mayor parte hombres, sobre todo a medida que se asciende en la escala social. Este fenómeno es el resultado al tomar en forma agregada la pobla ción negra y mulata, lo cual signific a que los jefes de hogar mulatos explican ese relativo descenso en el dato a gregado negros/mula tos, como antes se anotó. De nuevo, el factorde clase social tiende a operar, como lo habíamos advertido en el análisis de la Tabla 1, pero aparece aquí en forma determinante el ingrediente de género en las dos poblaciones "étnico-raciales", aunque de modo diferenciado al controlar por quintil de ing resos.

Es en el primerquintil de ing resos donde la población negra/mula ta registra el mayorporcentaje de jefesde hogar (verpara el total de la Tabla 2 el porcentaje de columna), $29.0 \%$, disminuyendo sistemátic a mente para los siguientes quintiles de ingreso, incrementándose obviamente la mestiza/blanca, hasta llegar en promedio en los quintiles cuarto y quinto a un $12.9 \%$ los jefes de hogar negros/ mulatos. El promedio en su conjunto para el Valle urbano entre los hogares completos es del $19.2 \%$, lo cual simplemente se relaciona con el peso demográfico de la 
73 Es usual que la edad del cónyuge en la mayorparte de los casos sea menor a la del jefe si no similar. Por esta razón, se ha tomado únicamente la edad del jefe del hogar como principal referencia de variable de control, con miras a simplificar el cruce de variables. población negra en la región urbana del Valle $(25 \%$ hacia el 2001) y más específicamente en Cali (26.5\%, Informe Cidse-ECV 2003, op. cit.), con una sobre concentración en los sectores populares, como lo muestra el mayor peso porcentual en los dos primeros quintiles.

Como nuestro estudio empíric o cualita tivo se refiere más bien a población a dolescente, presentamos la Tabla 3 , en la cual intentamos acercamos al efecto de la edad del jefe del hogar ${ }^{73}$ respecto al fenómeno de homogamia racial, diferenciando para jefes (porcentaje columna) y cónyuges (porcentaje fila). Adviértase, en primer lugar, que el mayorporcentaje de cónyuges de jefes en la población negra/mulata respecto al total de hogares completos se da en el grupo etáreo menor de 25 años (23.4\%), desc endiendo ligeramente en los otros dos grupos etéreos, lo cual estaría indicando la relativa importancia que tiene para este grupo "étnico-racial" las uniones en edades jóvenes, lo cual a su vez debe rela cionarse con lo a dvertido antes para la Tabla 2, respecto al mayor peso porcentual de jefes de hogarnegros/mula tos en el primero y segundo quintil de ingresos. Esto quiere decir una alta participación de uniones jóvenes en sectores populares, con una sobre representación de jefes de hogarnegros/mulatos.

Un segundo hallazgo interesante es el patrón diferente de las tasas de homogamia racial para la población negra/mulata, ya sea el jefe del hogar o la cónyuge, según el grupo de edad del jefe. Llama la atención que para los jefes de hogarmenores de 25 años negros-mulatos se tiene la mayor tasa de homogamia en ese grupo racial, descendiendo ligeramente en los otros dos grupos de edad; en cambio, para las cónyuges es al contranio: el grupo de menoredad signific a una significativa menorhomogamia - la más reducida de todas-, situándose en los otros dos grupos etéreos con altas tasas de homogamia. Una tendencia opuesta se registra en el caso de la población mestiza/blanca: losjefestienen una menor tasa de homogamia en el primer grupo etáreo y luego aumentan versus las mujeres cónyuges que tienden ligeramente a una mayor tasa en el primero y se reducen ligeramente en las siguientes. 
Tabla 3 - Homogamia de los hogares completos (nUCleAReS, extensos y compuestos), SegúN CARAC TERÍSTICAS RACIALES DEL J EFE DE HOGAR Y CÓNYUGE, Y EDAD DEL J EFE DEL HOGAR, PARA EL VALE URBANO (JUNIO 2003)

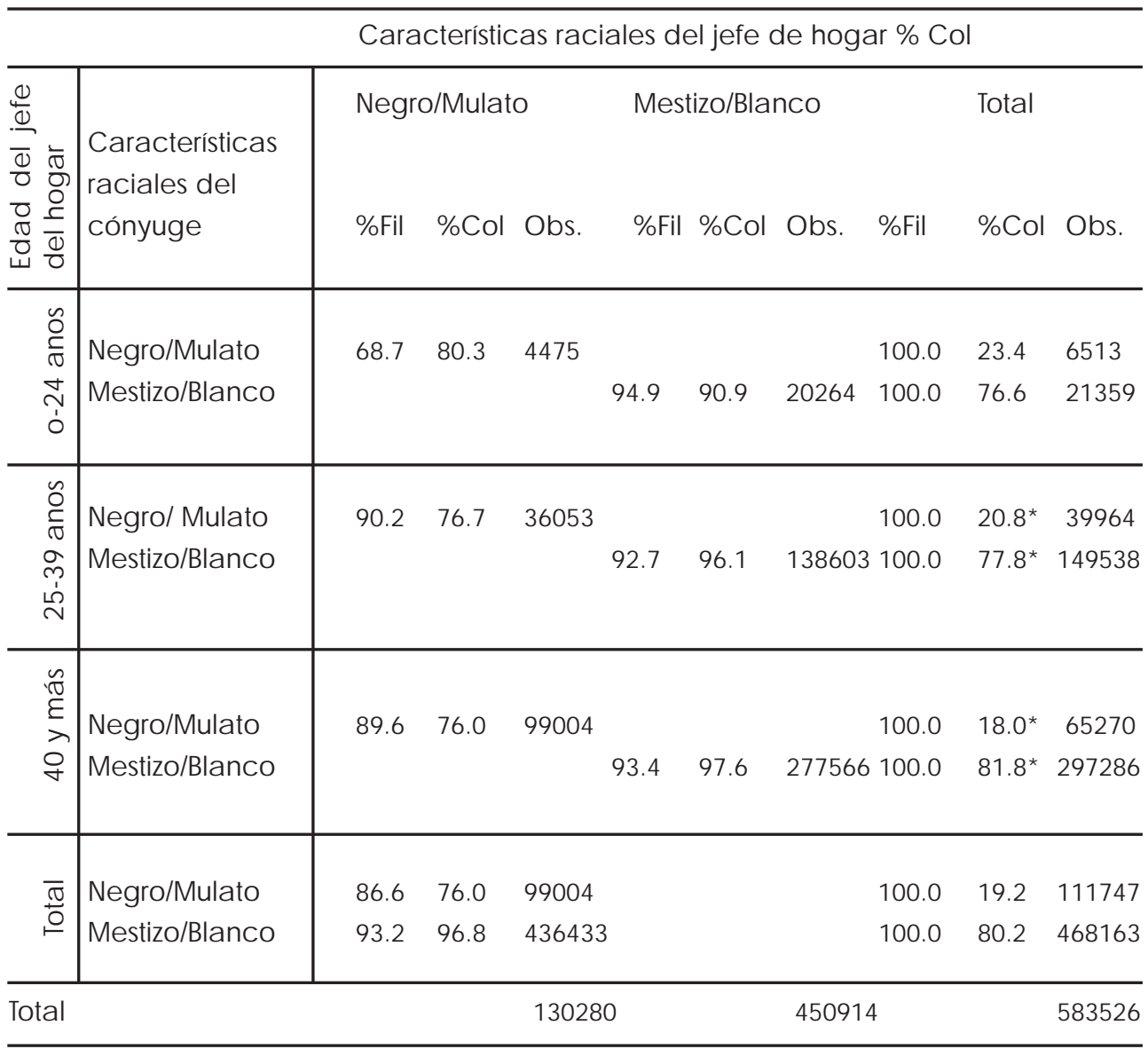

FUENTE: Encuesta de Ca lidad de Vida, Dane, junio de 2003. Procesa miento especial de los hoga res completos (con jefe de hogar y cónyuge; ya sean nucleares, extensos o compuestos), fueron excluidos los hogares unipersonales, monoparentales (nucleares, extensos y compuestos) y los colectivos.

* Los porcentajes de columna para el total en los grupos de edad 25-39 y 40 años y más no dan $100.0 \%$ debido a que faltan los valores pequeños de la población indígena y gitana, que ha sido excluida de este a ná lisis por los reducidos ta maños de muestra. Igua Imente sucede con el total de observaciones debido a ese reducido faltante. Únic amente se dejaron los porcentajes de fila y columna que permitan observar en forma clara la matriz.

El fenómeno observado de una significativa menor homogamia para la población negra/mulata en unión más joven, en el caso de las cónyuges, podría estar relacionado con los hallazgos más de tipo cualitativos, respecto a la tendencia hacia una mayor circulación de las mujeres negras/mulatas (pero también mestizas/blancas) de clases 
populares jóvenes (adolescentes y postadolescentes), vincula da sal sistema esc olar, por fuera del á mbito del ba mio cerrado en búsqueda de hombres con mejores capitales escolar y cultural, muchos de ellos no necesariamente negros/mulatos. Por el contrario, los jefes de hogar negros/ mulatos en ese rango de edad más joven presentarían estrategias más homogámicas, quizás también más de circulación en el interior del barrio, correspondiendo a los hombres de menorescapital escolary cultural. Porotro lado, también hay que tener en cuenta que una parte importante de las adolescentes y postadolescentes mujeres negras/ mula tas, que están en el sistema esc olar, como lo muestran los estudios cualitativos y algunos cuantita tivos, van a postergar el ejercic io de su sexualidad y una eventual unión quizás mucho más que las mujeres mestizas/blancas de su misma condic ión social. Esto último puede explic ar ta mbién la menor tasa de homoga mia racial en ese grupo de edad.

Para la población mestiza/blanca en la medida en que la homogamia racial es más elevada en los tres grupos de edad sin claros patrones de diferenciación por género y edad, se puede pensar en que la mayor homogamia para dicho grupo, a demás de serindependiente de la clase social (como se anotó para los datos de la Tabla 2), un fenómeno similar opera respecto a la edad del jefe y al género (mujer cónyuge u hombre jefe). En esta situación el efec to de género y edad es más relevante en la población negra/mulata, o mejor, el efecto de estas dos variables es diferente en los dos grupos "étnic o-raciales". Por supuesto, estos resultados presentarían mayores matices si se dispusiera de una información en la que se pudiesen diferenciar poblaciones negra y mulata, mestiza y blanca.

\section{Elementos para una discusión}

Dentro de las limitaciones de este artículo sobre el tema, hay que indicar que la información empírica se apoya en estudios anteriores sobre masculinidades, feminidades y prácticas de sexualidad de adolescentes y postadolescentes negros de sectores populares. Por ello, el máximo alcance es la elección de pareja para el noviazgo y eventualmente para establecer una unión, a unque esta última es menos probable en este ciclo de vida. A pesar de esto, los da tos permiten una a proximación muy preliminar al universo potencial de uniones jóvenes de la gente negra y mulata en relación con la población blanca y mestiza. En compensación se ha dispuesto de una información estadística de conjunto para toda la población afrocolombiana y no a froc olombiana en hogares completos de la ciudad y la región urbana a la cual 
pertenece Cali. La información cuantitativa tiene a su vez limitaciones porque es un procesa miento restringido a jefes de hogar y cónyuges presentes, por lo que no es estric ta mente una información de patrones de nupcialidad.

La ideología del a mor romántico continúa teniendo un peso preponderante en la construcción de los afectos, especialmente entre los jóvenes de las clases populares más excluidos y en los individuos con bajo nivel de escola ridad, donde los principales proyectos de vida aún giran en tomo al proyecto de matemidad y patemidad id ea lizadas. Sin embargo, las prácticas de los noviazgos y uniones revelan un desfase entre la ideología y el acceso al mundo adulto para mujeres (ser madres como primera opción en una situación de fuerte asimetría respecto al hombre) y hombres (ser padres sin condiciones de ejercer siquiera el rol de proveedor). De este modo, la ideología ayuda a la reproducción de las formas de dominación masculina en las clases populares y las instituciones más rela cionadas con ella, como el grupo de pares masculino.

Para las mujeres y los hombres negros-as y ta mbién mula tos-as en condiciones de exclusión social, desertores escolares y atadas en el caso de las mujeres a los roles doméstic os, sus trayec torias de vida no les permite salir del entorno intrabarrial, circulando en un mercado erótico tra dic ional en el que los resulta dos son noviazg os y uniones con altas tasas de viudez (debido a la participación en actividades ilíc itas de riesgo de los jóvenes adolescentes) y embarazos tempranos que no garantizan relaciones de pareja estable.

En forma contraria a la situación precedente, los cambios que han experimentado varios adolescentes de clases populares en las formas de vivenciar su sexualidad, to mar dec isiones, a sumir compromisos y construir relaciones de pareja, estarían evidenciando algunas fisuras significativas dentro del modelo de amor romántico tradicional, como por ejemplo una actitud más reflexiva hacia los roles de género que habrían aprendido en su casa y durante su período de formación escolar así como una pérdida considerable de influencia del grupo de pares. Sin embargo, siguen operando los estereotipos raciales sexuales en el mercado erótico de los grupos más educados, lo que va en contravía de los avances de desmitific ación del amor romántic 0 . Escierta la construcción que han hecho algunas mujeres, principalmente de clases populares y clases medias bajas, de un proyecto de vida en el cual la sexualidad está supeditada a otras metas que estarían relacionadas con sus logros profesionales y laborales. Desafortunadamente este fenómeno muchas veces significa una renuncia al ejercicio de la sexualidad 
durante el sistema escolar. Esto se observa en la población negra y mulata femenina más escolarizada de secundaria y universitaria, en el contexto de una presión de los estereotipos raciales que natura lizan el cuerpo erótico.

Las fisuras que se estarían generando dentro del modelo del amor romántico, y sus implicaciones en la construcción de los afectos, evidencian una reducción del merca do erótico en la elección de pareja para los jóvenes de clases populares en la medida en que la oferta de mujeres disponibles de su barriada se focaliza sobre hombres de otros sectores de la ciudad, con mejores capita les soc ia les y cultura les, que prometen una movilidad social ascendente y una relación de pareja caracterizada por una mayor reciprocidad en el plano afectivo. No obstante, por las condiciones antes descritas, esta orientación de las preferencias en la elección de pareja en una buena medida no es exitosa.

La construcción del afecto y la elección de pareja de los jóvenes de sec tores popula res en Cali son seña lizadas por una serie de procesos colectivos que apuntan al tipo de estruc tura social en la que la dimensión racial constituye un componente en interacción con las clases y el género. Es en este cuadro que la relación entre afec to y losca mbios en el amor romántico y su papel en la elección de pareja se desarrollan a través de las trayectorias de vida individuales. Así, la elección del cónyuge descansaría, pues, sobre un juego de constricciones morfológicas, de

${ }^{74}$ KAUFMANN, 1993 y 2003. disposiciones inconscientes y de objetivos estratég ic 0 s. $^{74}$ Para este autor la elección del cónyuge no funcionaría al azar; según el lugar ocupado en la sociedad, las proba bilida des esta dístic as circ unsc ribiría n los compa ñeros potencia les al interior de un círculo rela tivamente estrecho, lo cual no signific ańa que la posibilidad de otraselecciones no pudiese considerarse puesto que el mercado matrimonial es, de hecho, muy amplio, abierto, fluido e incierto. Esta relativa fluidez en el caso de Cali se a plicaría ante todo a la población mulata y en segundo lugar, a la mestiza. Menos para la negra y la blanca. Porotra parte, el fenómeno de la incertidumbre en la sociedad colombiana pasa por el color de piel, lo que restringe la escogencia erótica-sexual.

En relación con la escala de proximidad homogámica, los individuos se situarían a una distancia relativamente grande y no en dos categorías distintas y fijas (homóga mo o no homóga mo). Por ello, la homogamia debería ser analizada como un proceso dinámico con el objetivo de permitir comprender que la constricción del mercado de candidatos-as potenciales no produciría automáticamente una disminución de las elecciones 
75 KAUFMANN, 1993 y 2003.

${ }^{76}$ KAUFMANN, 2001, p. 172 y 173.

77 Ver KAUFMANN, 2004, sobre las identidades como invención del sí mismo. posibles: cuando algunas condiciones crean la situación de un 'pequeño mercado' aparente, los-as compañerosas no dudan en alejarse aún más de las reglas homogámicasy de correspondencia, evidenciando de este modo que la constricción del mercado no limita la elección, sino que por el contra rio la aviva e incita a resistir la a tra cción homogá mica. Esto esa pa rentemente vá lido para los grupos de jóvenes escolarizados, mujeres y hombres negros y mulatos, de barrios populares cuya elección de pareja para el noviazgo y una eventual unión se orienta hacia otrosbarrios y espa cios urba nos (universidad pública). Igualmente, Kaufmann ${ }^{75}$ señala que la dinámica de los procesos de a tra c ción permite comprendercómo cambian las reglas de correspondencia a partir de estrategias de evitamiento, una vez que las elecciones aparentemente atípicas se multiplican y definen nuevas reglas. Esta estrategia de evitar al otro es en particular válida en el caso de la población blanca colombiana (datospara Cali), cuya homogamia es la más alta y cruza todas las clases sociales.

Si se asume una perspectiva más dinámica de las prácticas de elección de pareja en contextos específicos, además del papel desempeñado por el habitus como productor de homogamia, en situaciones de mayor fluidez entre las trayectorias individuales de mujeres y hombres escolarizados que se separan de cuadros de clase muy restrictivos como los de clases populares en condiciones de exclusión y se enma rc an en otra sestra tegias de elección de pareja y de vivencia de la sexualidad, es necesario dar un papel analítico más activo al individuo en su esfuerzo de movilidad social. Para este efec to es útil la ca tegoría de hábito (habitude), de acuerdo con Ka ufmann ${ }^{76}$ en cuanto esquema operatorio reflexivo que ayuda a la incorporación de nuevos elementos diferentes al origen social, que a diferencia del habituses más bien a c tivo. Mientra s el habitus en el sentido de Bourdieu tendería a favorecer el enclasamiento homogámico, el hábito se inscribe más en las estrategias de reclasamiento y en las modalidades de hipergamia. La dinámica social combina así las dos dimensiones - una pasiva, la otra activa - que producen diferentes identidades en los desarrollos de los procesos de individuación. ${ }^{77}$

\section{Referencias bibliográficas}

AGIER, Michel. "Lugares y redes. Las mediaciones de la cultura urbana". Revista Colombiana de Antropología, Bogotá, ICAN (Instituto Colombiano de Antropología), v. XXXII, p. 221-243, 1995. 
ARAUJ O, Clara; SCALON, Celi (Orgs.). Gênero, família e trabalho no Brasil. Rio de Ja neiro: Editora FGV, 2005.

BADINTER, Elisa beth. L'Amour en plus. Pa ris: Fla mmarion, 1980. . L'un est l'autre. Paris: Odile J acobs, 1986.

BARBARY, Olivier; URREA, Femando (Eds.). Gente negra en Colombia :diná micas soc iopolitic as en Cali y el Pacifico. Medellín: Edic iones CIDSE/UNIVALE - IRD - COLCIENCIAS, Editorial Lea lon, 2004.

BAWIN-LEGROS, Bernadette. "Intimacy and the New Sentimental Order". Current Sociology, Londres, Sage Public ations, v. 52, n. 2, p. 241-257, Mar. 2004.

BERQÚO, Elza. "Nupcialidade da população negra". Revista Brasileira de Estudos da População, Campinas, NEPO/ UNICAMP, n. 11, p. 8-43, 1987.

BOURDIEU, Pierre.. La distinction. Critique sociale du jugement. Pa ris: Minuit, 1979. . "De la règ le auxstra tégies". In :

Paris: Éd. de Minuit, 1987. p. 75-93.

CHAUMIER, Serge. "La fission a moureuse, un nouvel art d'aimer". In: SING LY, François de (dir.). Être soi parmi les autres. Famille et individualisation. Paris: L'Harmattan, 2001. Collection Logiques sociales. Tome 1. p. 41-54.

DANE (Departa mento Nacional de Estadística). Base de da tos de la Encuesta de Ca lidad de Vida 2003. Proyecto CidseDane, 2004.

DOMÍNG UEZ, Marta. A gendered analysis of gangs in Siloe. 1999. Disertación (Tesis de Maestría) - Lond on Sc hool of Economics and Political Science, London.

Encuesta Cidse-Banco Mundial-Alcaldía de Cali: "Acceso y percepción de los servicios ofrecidos por el municipio de Santia go de Cali". Bases de da tos Cidse, Septiembre 1999.

GIDDENS, Anthony. The Transformation of Intimacy: Sexuality, Love and Eroticism in Modern Societies. Cambridge: Polity Press, 1992.

GAMBOA, Jorge Augusto M. El precio de un marido. El signific ado de la dote matrimonial en el Nuevo Reino de Granada. Pamplona (1570-1650). Bogotá: Instituto Colombiano de Antropología e Historia (ICANH), 2003. Colección Cuademos Coloniales.

GIRARD, Alain. Le Choix du conjoint. Paris: Presses Universitaires de France (PUF) - INED, 1964.

Grupo de investigación sobre pobreza y desigualdad. Informe final. Condiciones sociodemográficas, pobreza y desigualdad en el Valle del Cauca: un aná lisis basado en la encuesta de calidad de vida DANE 2003. Coordinado por Femando Urrea G. Cali: Facultad de Ciencias Sociales y Económicas, Centro de 
Investigación y Documentación Socioeconómica (CIDSE), Universidad del Valle, 2004.

HILL COLLINS, Patricia. Black Sexual Politics. African Americans, Gender, and the New Racism. New York: Routledge Taylor \& Franc is Group, 2005. p.119-148.

KAUFMANN, Jean-Claude. Sociologie du couple. Paris: Presses Universita ires de France (PUF), 1993 y 2003. 2001.

. Ego. Pour une sociologie de l'individu. Paris: Nathan,

. L'Invention de soi. Une théorie de l'identité. Paris:

Armand Colin, 2004.

KELLERHALS, J ean et al. Mic rosociologie de la fa mille. Paris: Presses Universita ires de France (PUF), 1984 y 1993.

LIPOVETSKY, Gilles. La tercera mujer. Barcelona: Anagrama, 1997.

MARG ULLSS, Ma rio; URREST, Marcelo. "La construc ción social de la condición de juventud". In: CUBIDES, Humberto; LAVERDE, María Cristina; VALDERRAMA, Carlos Ed ua rdo (Eds.). Viviendo a toda. Bogotá: Universidad Central Sig lo del Hombre Editores, 1998. p. 3-21.

MORITZ SCHWARCZ, Lilia. "Nem preto nem branco, muito pelo contrário: cor e raça na intimidade". In: NOVAIS, Femando A. (Dir.). História da vida privada no Brasil. São Paulo: Companhia das Letras, 1998. v. 4 (Volume organizado por Lilia Moritz Sc hwarcz.). p. 173-244.

QUINTíN, Pedro; RAMÍREZ, Héctor Fabio; URREA, Femando. "Relaciones interraciales, sociabilidades masculinas juveniles y segregación laboral de la población a frocolombiana en Cali". Documento de Tra bajo CIDSEIRD, n. 49, Facultad de Ciencias Sociales y Económicas, Centro de Investigación y Documentación Socioec onómica (CIDSE), 2000.

RODRÍGUEZ, Pablo (Coord.). "La familia en Colombia". In: . La familia en Iberoa mérica 1550 - 1980. Bogotá: Centro de Investigación sobre Dinámica Social, Universidad Extemado de Colombia, Convenio Andrés Bello, 2004. p. 247-288.

SEGALEN, Martine. Sociologie de la famille. Paris: Armand Colin, 1993.

SHORTER, Edward. Naissance de la famille moderne. Paris: Éditions du Seuil, 1975 y 1977.

SINGLY, François de. Sociologie de la Famille Contemporaine. Paris: Nathan, 1993.

SING LY, Franç ois de (Dir.). "Préface. La na issance de l'individu individualisé etses effets sur la vie conjuga le et familiale". In: Être soi parmi les autres. Famille et individualisation. Paris: L'Ha rmattan, 2001. Collection Logiques sociales. Tome 1. p. 5-21. 
URREA, Femando. "Dinámica sociodemog ráfica, mercado laboral y pobreza urbana en Cali durante las décadas de los años 80 y 90". Revista Coyuntura Social, Bogotá: FEDESARROLLO, n. 17, p. 89-164, nov. 1997.

URREA, Fernando; QUINTÍN, Pedro. Jóvenes negros de barriadas populares en Cali: entre masculinidades hegemónicas y marginales. Cali: F. Chagas/CidseUnivalle, 2000.

URREA, Fernando; QUINTÍN, Pedro. "Subjetividades masculinas en jóvenes de clases suba ltemas urbanas". Cahiers des Amériques Latines, n. 39. Dossier Rapports de Genre et Masculinités. Paris: Iheal Éditions, 2002. p. 83-107.

URREA, Femando. "El grupo de pares en la construcción masculina de jóvenes de clases sub altemas". Ponencia presentada en la conferencia regional VARONES ADO LESCENTES: CONSTRUCCIÓN DE IDENTIDADES DE GÉNERO EN AMÉRICA LATINA YELCARIBE. SUBJ EIVIDADES, PRÁC TICAS, DEREC HOSY CONTEXTOSSO C IOC ULTURALES. Santiago de Chile, 6-8 de noviembre 2002.

URREA, Femando; C ONGO LINO, Ma ry Lily; HERRERA, He mán Darío. "Sociabilidades y sexualidad entre jóvenes de sectores populares de Cali". Ponencia presentada en VII CONG RESSO LATINO AMERICANO DE CIÊNCIASSO CIAIS E SAÚDE, 19 a 23 de outubro de 2003, Hotel Angra dos Reis, Brasil, 2003.

URREA, Femando; CONG OLINO, Ma ry Lily; HERRERA, He mán Darío; REYES, José Ignacio; BOTERO, Waldor. "Comportamientos sexuales e incidencia de los programas de salud sexual y reproductiva en estudiantes de secundaria de sectorespopularesy de la universidad pública en la ciudad de Cali, Colombia". Cad. Saúde Pública, v. 22, n.1, p. 209-215, 2006.

VARGAS, Elvia; HENAO, Jua nita; G ONZÁLEZ, Constanza. "Fecundidad adolescente en Colombia: Incidencia, tendencias y determinantes, un enfoque de historia de vida". Informe final del estudio cualita tivo. Proyecto financiado con la cooperación de Colciencias y el FNUAP. Centro de Estudios sobre Desa rrollo Económico, CEDE; Universidad de los Andes, Bogotá. 2004.

VIVEROS, Mara; CAÑON, William D. "Pa'Bravo... yo soy candela, palo y piedra. Los Quibdoseños". In: VALDÉS Teresa; OLAVARRÍA J osé (Eds.). Masculinidad/es. Poder y Crisis. Santiago, Chile: Edic iones de las Mujeres n. 24, 1997. p. 125-138.

VIVEROS, Mara. "Dionisios negros: sexua lidad, corporalidad y ord en racial en Colombia". In: FIGUEROA, M. B.; SAN MIGUELP. E. (Eds.). ¿Mestizo yo?. Bog otá: CES-Universidad Nacional de Colombia, 2000a. p. 95-130. 
"Paternidades y masculinidades en el contexto colombiano contemporáneo, perspectivas teóricas y a nalític as". In: FULLER, Norma (Ed.). Paternidades en Améric a Latina. Lima: PUCP, 2000b. p. 91-127.

VIVEROS, Mara; HERNANDEZ, Franklin Gil. "¿Educadores, orientadores, terapeutas? J uventud, sexualidad e intervención social". Cad. Saúde Pública, v. 22, n. 1, p. 201-208, 2006.

WADE, Peter. Gente negra, nación mestiza. Dinámicas de las identidades raciales en Colombia. Bogotá: Ed itorial Universidad de Antioquia/Instituto Colombiano de Antropología/Siglo del Hombre Editores/Ediciones Uniandes, 1997a. $1997 b$.

Race and Ethnicity in Latin America. London: Pluto,

WELER, Wivian. "A presença feminina nas (sub)culturas juvenis: a arte de se tornar visível". Revista Estudos Feministas, v. 13, n. 1, p. 107-126, 2005.

[Recebido em agosto de 2005 e aceito para publicação em maio de 2006]

\section{Affection and Couple Election among Teenagers from Popular Sectors of Cali}

Abstract: This article explores the affection and the couple election production logics among teenag ers from heterog eneous popular sec tors of Cali city (Colombia), acc ording to class, gender and race factors. Without seeking to look directly into the conjugality, anyway the text enters in the matter of couple's election, under the restrictions of adolescent and post adolescent life cycle of our research program through the courtship, eventually with the option to cohabit and to have an offspring; in accordance with the information picked up to level of the interviews and the focal groups. In second place, when having the opportunity of a statistical data through household survey series between 1998 and the 2003 in Cali and the Valle del Cauca urban region, where Cali is placed, on Afrocolombian and non Afrocolombian population, we have been able to attempta first approach to the racial homogamy phenomenon for the complete households (itmeans, with spouse's presence), esta blishing the nec essa ry links with the qual litative data to look from a macro social perspective the behavior of these logic s a mong the teenagers. For that reason, the class, gender and race factors are seen through the racial homogamy category, in the sense of coming closer to the social constraints of the sexuality as a social practice, the affection and the intent of conjugal couple conformation in the Cali society.

Key Words: Affection, Romantic Love, Couple Election, Gender, Social Class and Racial Homogamy. 